\title{
Tuberculosis research in South Africa over the past 30 years: From bench to bedside
}

\author{
R M Warren, ${ }^{1} \mathrm{PhD} ; \mathbf{N}$ Ismail, ${ }^{1} \mathrm{PhD} ; \mathbf{N}$ N Chegou, ${ }^{1} \mathrm{PhD} ;$ G Theron, ${ }^{1} \mathrm{PhD} ; \mathbf{G}$ Walzl, ${ }^{1} \mathrm{FRCP}, \mathrm{PhD} ; \mathbf{S}$ T Malherbe, ${ }^{1} \mathrm{MD}, \mathrm{PhD}$; \\ C J Kinnear, ${ }^{1} \mathrm{PhD}$; G D van der Spuy, ${ }^{1} \mathrm{PhD}$; W Goosen, ${ }^{1} \mathrm{PhD} ;$ M A Miller, ${ }^{1} \mathrm{DVM}, \mathrm{PhD} ; \mathrm{A}$ H Diacon, ${ }^{2} \mathrm{MD}, \mathrm{PhD} ; \mathrm{P}$ D van Helden, ${ }^{1} \mathrm{PhD}$ \\ ${ }^{1}$ SAMRC Centre for Tuberculosis Research/DST-NRF Centre of Excellence for Biomedical Tuberculosis Research Division of Molecular Biology and \\ Human Genetics, Faculty of Medicine and Health Sciences, Stellenbosch University, Cape Town, South Africa \\ ${ }^{2}$ TASK Applied Sciences, Cape Town, South Africa
}

Corresponding author: $R$ Warren (rw1@sun.ac.za)

The South African Medical Research Council Centre for Tuberculosis Research has a rich history of high-impact research that has influenced our understating of this hyper-epidemic which is further exacerbated by the emergence and spread of drug-resistant forms of the disease. This review aims to summarise the past 30 years of research conducted in the Centre which has influenced the way that tuberculosis (TB) is diagnosed and treated. The review includes the development of new technologies for rapid screening of people with probable TB and the repurposing of human diagnostics for wildlife conservation.

S Afr Med J 2019;109(11 Suppl 1):45-52.https://doi.org/10.7196/SAMJ.2019.v109i11b.14249

In April 1993, the World Health Organization (WHO) declared tuberculosis (TB) a global emergency. ${ }^{[1]}$ In 1996, the South African National Department of Health declared TB a national emergency and TB treatment became a national priority. ${ }^{[2,3]}$ It was clear to us that inadequate attention was being given to this disease, which included inadequate tools to diagnose and treat the problem. The Centre for Tuberculosis Research (CTR) (Table 1) therefore sought to embark on the active development of novel methods for the diagnosis and genotypic characterisation of the causative agent, Mycobacterium tuberculosis. This programme led to the birth of the science of molecular epidemiology, ${ }^{[4,5]}$ which allowed tracking of the strains through DNA fingerprinting ${ }^{[6,7]}$ (Fig. 2), spoligotyping ${ }^{[8-10]}$ and mycobacterial interspersed repetitive units variable number of tandem repeat (MIRU-VNTR) typing. ${ }^{[1]}$ This was also an era of gene discovery, which provided new insights into the mechanisms of drug resistance. ${ }^{[12,13]}$ The CTR used these methods to challenge established dogmas, ${ }^{[14]}$ such as whether reinfection occurs, ${ }^{[15]}$ whether primary infection with a drug-resistant strain occurs ${ }^{[16,17]}$ and whether mixed or multiple infection occurs. ${ }^{[18,19]}$ For example, our findings that reinfection and multiple infection are common in $\mathrm{TB}$, prompted much discussion and thinking, with broad implications ranging from vaccine use to diagnostics, antibiotic usage and preventive therapy.

\section{Diagnostics targeting Mycobacterium tuberculosis}

In the late 1980s, scientists at the CTR recognised the importance of the polymerase chain reaction (PCR) as a potential diagnostic technique. In order to use this technology, the CTR built the firstever automated PCR machine in Africa. Subsequently, the technology was used to develop an assay to detect resistance-associated genetic mutations to first-line anti-TB drugs. ${ }^{[59]}$ This research introduced clinicians and scientists in Africa to the concept of genetic drug susceptibility testing (gDST). The recent commercialisation of this technique by various diagnostic companies enabled these assays to form an important component of the diagnostic algorithm. ${ }^{[60]}$ The CTR has been involved in testing these assays; for example, in collaboration with the National Health Laboratory Service (NHLS), the CTR evaluated the GenoType MTBDRsl assay, demonstrating
Table 1. History of the SAMRC Centre for Tuberculosis Research

The beginnings of the Centre for Tuberculosis Research in fact predate the MRC. In 1957, the Faculty of Medicine and Health Sciences (FMHS) of Stellenbosch University began operating out of premises at Karl Bremer Hospital. Around 1960, a Council for Scientific and Industrial Research Degenerative Diseases Group under the directorship of Professor Andries Brink, later to be the first president of the MRC and second dean of the FMHS, was started. The MRC was established in July 1969 and the group was transferred and renamed the MRC Unit for Molecular and Cellular Cardiology. In 1970, the Unit moved to new premises in the FMHS within the Department of Internal Medicine. In 1972, the Unit moved to the FISAN building and from 1974 was hosted in a new Department of Medical Biochemistry, both headed by Professor Wieland Gevers. In 1977, Professor Gevers moved to the University of Cape Town and the directorship of the Unit was passed on to Professor Andre Bester. The Unit became the Centre for Molecular and Cellular Biology with a broader mandate in 1988. In 1990, Professor Paul van Helden became director of the MRC Centre, and in 2014 the Centre became known as the SAMRC Centre for Tuberculosis Research (CTR) with a clear mandate to focus efforts on TB. Professor van Helden retired in 2016 and Professor Rob Warren is the current unit director. Over the past 30 years, the research conducted in the CTR has significantly influenced understanding of the epidemiology of tuberculosis disease, development of new diagnostics, provided new insight into biomarkers of disease, and translated human diagnostics for wildlife conservation (Fig. 1)

excellent sensitivity and specificity for diagnosis of $\mathrm{TB}$ and even fluoroquinolone and aminoglycoside resistance, ${ }^{[61,62]}$ which has now been implemented into routine care. To simplify the interpretation of GenoType assays, a FluoroType assay based on linear-after-theexponential (LATE)-PCR and Lights-On and Lights-Off technology, was developed by the CTR in collaboration with Professor Wangh ${ }^{[63]}$ 


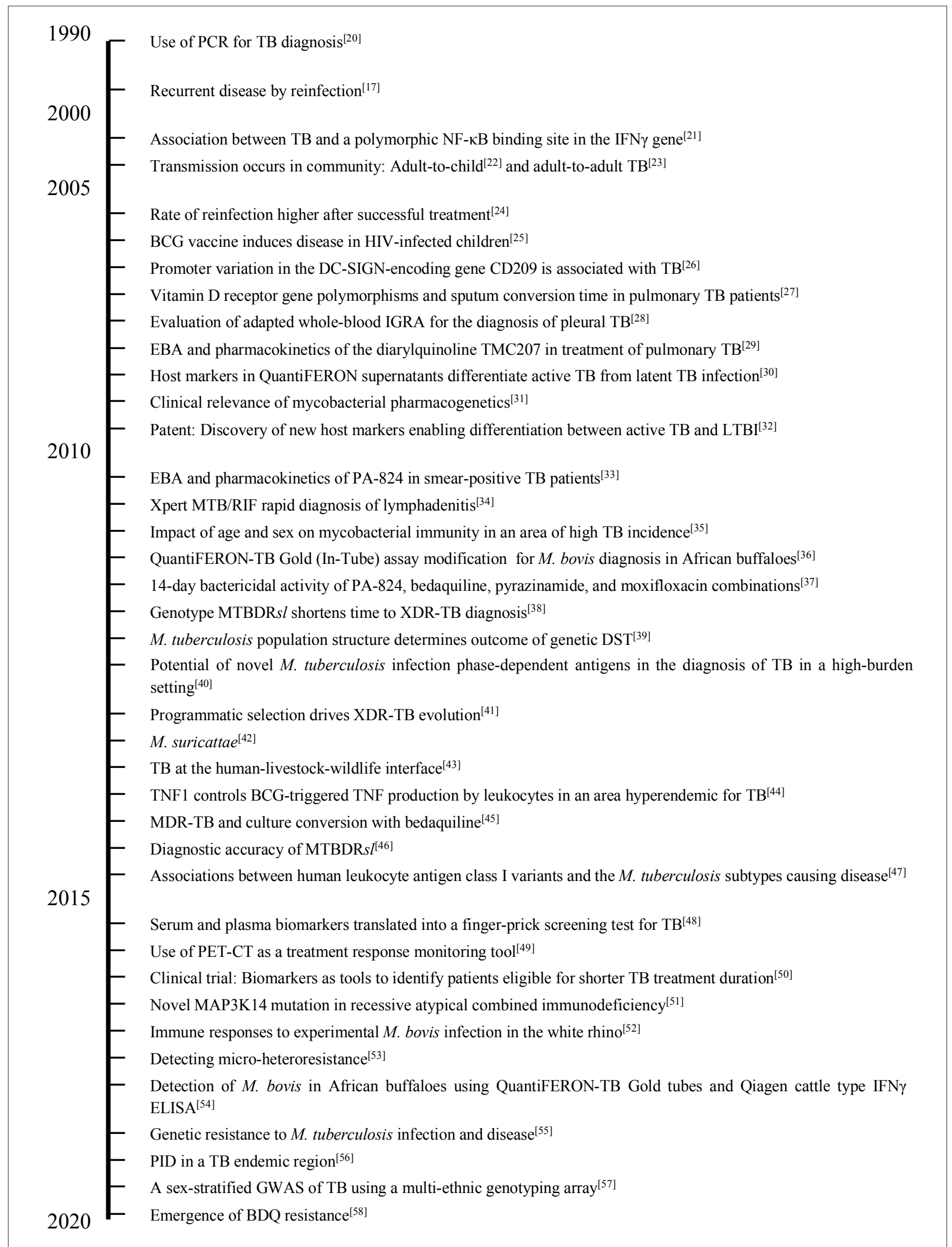

Fig. 1. Timeline of key contributions over 30 years from the Centre for Tuberculosis Research to molecular epidemiology, diagnosis, clinical studies and animal studies related to tuberculosis infection. $(P C R=$ polymerase chain reaction; $T B=$ tuberculosis; $N F-\kappa B=$ nuclear factor kappa-B; IFN $\gamma=$ interferon gamma; $B C G$ = bacille Calmette-Guérin; IGRA = interferon gamma release assay; $E B A=$ early bactericidal activity; $L T B I=$ latent $T B$ infection; TNF1 = tumour necrosis factor 1; PET-CT positron emission tomography - computerised tomography; PID = primary immunodeficiency disorders; GWAS = genome-wide association study; $B D Q=$ Bedaquiline. $)$ 
and commercialised by Hain Lifescience. This assay has been extensively evaluated by the CTR and showed similar sensitivities as the Xpert MTB/RIF assay for M. tuberculosis detection from sputum samples but with the added advantage of further insight into the molecular mechanisms of resistance for both isoniazid and rifampicin. ${ }^{[63]}$

The implementation of gDST into routine care provided researchers the unique opportunity of determining the utility of these assays on non-sputum samples, including fine-needle aspirate biopsies (FNAB). In collaboration with the NHLS, we developed a protocol for FNAB, using the Xpert MTB/RIF assay, ${ }^{[64]}$ where the sensitivity and specificity for detecting M. tuberculosis in FNAB were $96.7 \%$ and $88.9 \%$ for adults $^{[34]}$ and $80 \%$ and $93.8 \%$ for children, respectively ${ }^{[65]}$ These data contributed to the WHO's recommendation for diagnosing extrapulmonary TB using the Xpert MTB/RIF assay.

Defining the phenotype-genotype association remains critical for the acceptance of gDST. The CTR was the second group globally to evaluate and help develop the Epicenter software (linked to the MGIT 960 instrument), which allowed the determination of minimum inhibitory concentration (MIC) values and pairing these to genotypic data. These studies provided new insight into the genetic basis of resistance to capreomycin, amikacin, ofloxacin, moxifloxacin and ethambutol. ${ }^{[6-69]}$ Much of these data have contributed to the WHO technical manual for DST of antibiotics used in the treatment of TB. ${ }^{[70]}$
Careful re-evaluation of isoniazid resistance confirmed that inh $A$ promoter region mutations conferred low-level isoniazid resistance and ethionamide cross-resistance. Given that these mutations are easily detected by the MTBDRplus assay, we developed a policy brief requesting this information to be shared with clinicians to ensure standardised multidrug-resistant (MDR) TB treatment could be adjusted accordingly. ${ }^{[71]}$ More recently, we queried the prediction of rifampicin resistance by the Xpert MTB/RIF assay, as MIC testing clearly indicated that not all $r p o B$ mutations confer phenotypic resistance above the critical concentration $(1 \mu \mathrm{g} / \mathrm{mL}$, used to differentiate susceptible from resistant). ${ }^{[72]}$ We have proposed that patients with reduced susceptibility to rifampicin could benefit from either high-dose rifampicin or an alternative rifamycin, namely rifabutin. ${ }^{[73]}$ Clinical trials are now underway to evaluate the efficacy of such regimens but are expected to have great value in certain patients with XDR-TB (http://task.org.za/clinical-trials/).

DST remains technically challenging and it is imperative that alternative molecular-based methods are developed. This is particularly true for pyrazinamide DST, and the CTR has developed a simple workflow to enable detection of $p n c A$ mutations in clinical specimens ${ }^{[74]}$ within a 48 -hour period. Using this assay, we have shown that over $30 \%$ of MDR-TB cases and $>90 \%$ of extensively drugresistant $(\mathrm{XDR})-\mathrm{TB}$ cases have associated PZA resistance routinely

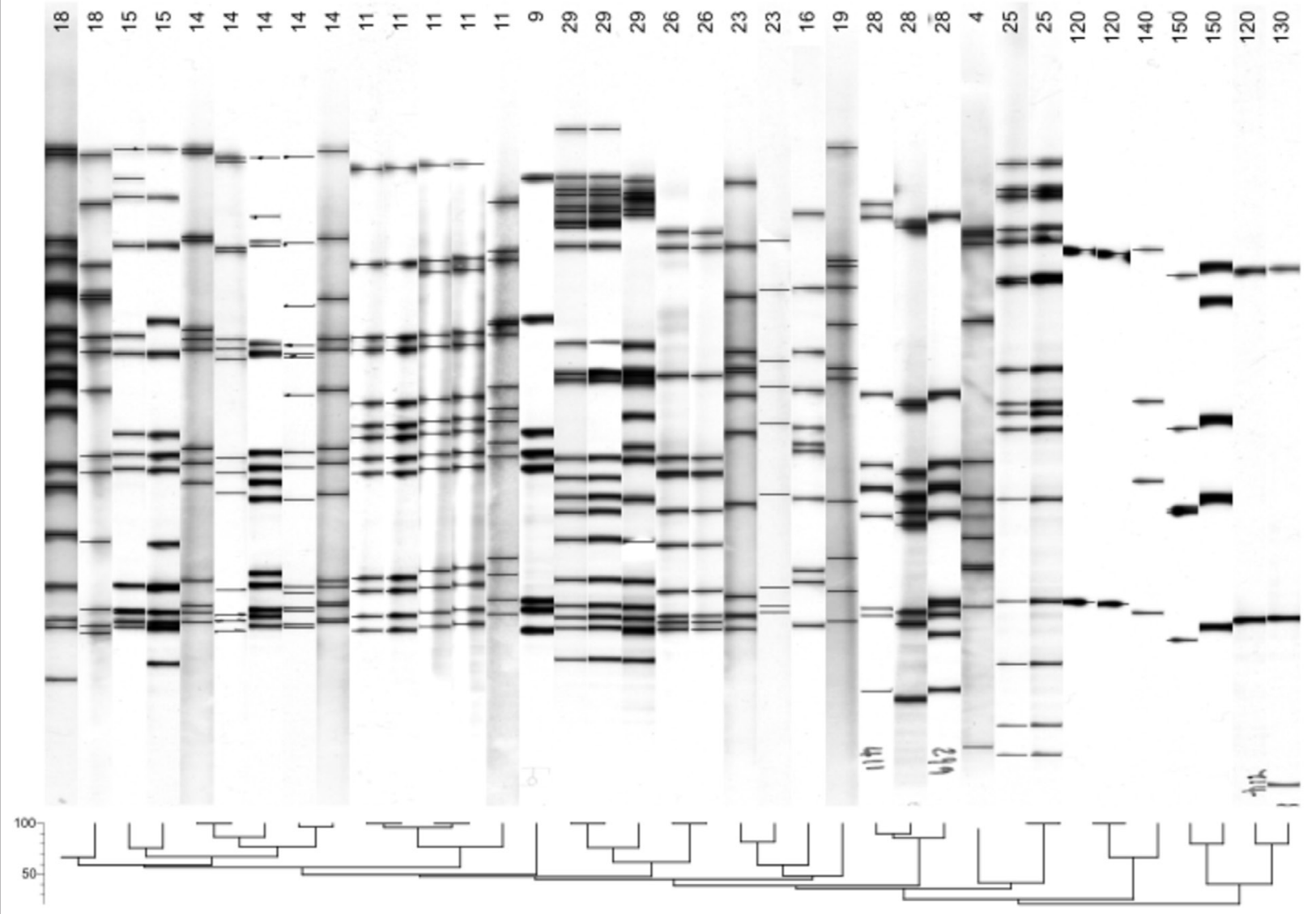

Fig. 2. A selection of IS6110 restriction fraction length polymorphism fingerprints from M. tuberculosis isolates of various representative strain families, clustered by similarity (Dice co-efficient) (below figure). The dendrogram was constructed using the UPGMA algorithm. Lane numbers are indicated by the first row of numbers, with the strain family identifiers in the second row. The figure was generated in Gelcompar (TM) ver. 6.5. Band positions are marked. Isolates with a similarity index $>90$ reflect transmission. 
undiagnosed $^{[75]}$ which, together with the strong association between ethambutol resistance and MDR-TB, ${ }^{[68]}$ undermines the efficacy of standardised MDR treatment regimens. Ineffective treatment of MDR-TB has allowed the emergence of additional resistance, culminating in XDR-TB, which we termed programmatic selection. ${ }^{[41]}$ These XDR-TB strains are now widespread and largely resistant to available anti-TB drugs and are on the verge of acquiring resistance to new and repurposed drugs. This highlights the need for comprehensive DST prior to treatment initiation to ensure improved outcomes. Through partnerships with the ReSeqTB platform, ${ }^{[76]}$ the CTR continues to contribute by providing whole genome sequence (WGS) data as well as comprehensive phenotypic data. This contribution is essential for the interpretation of WGS data as a diagnostic to guide treatment of DR-TB. ${ }^{[77]}$ Our diagnostic work has provided technical and scientific services to various provincial health departments, the gold mines, some state hospitals and various TB clinics.

Diagnostics are not only about the technology, but also its application in a realworld setting. We conducted a systematic review done as part of a WHO process to directly inform policy on products for $\mathrm{TB}$ diagnosis. ${ }^{[78]}$ We also investigated the South African (SA) TB care cascade, which is a tool by policymakers to set goals for strengthening the $\mathrm{TB}$ programme. ${ }^{[79]}$ Furthermore, we described innovative approaches for how material typically discarded by laboratories can be used for detailed drug susceptibility testing (thus alleviating the need for additional specimen collection) ${ }^{[80]}$ We recently identified widespread suboptimal performance of the only commercial molecular test for multidrug resistance (MTBDRplus) across dozens of laboratories worldwide and, importantly, demonstrated how this can be corrected by changing the conditions used for DNA amplification. ${ }^{[81]}$ This is now in the process of being incorporated into $\mathrm{WHO}$ external quality assessment processes for $\mathrm{TB}$ laboratories.

\section{The potential of immune-based} point-of-care tests for TB

Despite the amazing progress made in diagnostics targeting the bacillus, there is still much room for improvement, perhaps targeting the host. The use of interferongamma (IFN- $\gamma$ )-based tests in the diagnosis of TB infection is widely known and hence we evaluated the accuracy of these tests in our high-burden settings. We were amongst the first to show that ex vivo (unprocessed) pleural fluid IFN $-\gamma$ showed strong potential in the diagnosis of pleural TB. ${ }^{[28]}$ Following the publication of these findings, a highly cited editorial about our work was written, ${ }^{[82]}$ followed by several validation studies in low- and high-burden settings. At least one company is now developing an ex vivo pleural fluid IFN- $\gamma$ point-of-care test for the disease. ${ }^{[83]}$ We showed that there was high discordance between three known tests for M. tuberculosis infection (tuberculin skin test (TST), QuantiFERON TB Gold and T SPOT. TB) both in HIV-infected and -uninfected adults and children. ${ }^{[84]}$ These studies confirmed the limited value of the new and relatively expensive interferon gamma release assays (IGRAs) over the TST in high-burden countries such as SA. Findings from these studies were replicated in other parts of the world and our articles have been included in meta-analyses that contributed to policy statements on the use of IGRAs. ${ }^{[85,86]}$

Development of a point-of-care fingerprick blood-based test for TB Following our findings that IGRAs were not necessarily useful in high-burden settings, we were the first to report that the use of three host markers, produced by $T$ cells after stimulation of whole blood with the antigens that are used in IGRAs (ESAT6/CFP10/TB7.7), showed potential as a tool for the diagnosis of active TB (South African Patent: ZA 2009/05156). ${ }^{[30]}$ Similarly, we were one of the first groups conducting large-scale studies on the use of alternative antigens (other than those used in IGRAs) as diagnostic candidates for TB disease. We showed that combinations between different $M$. tuberculosis infection

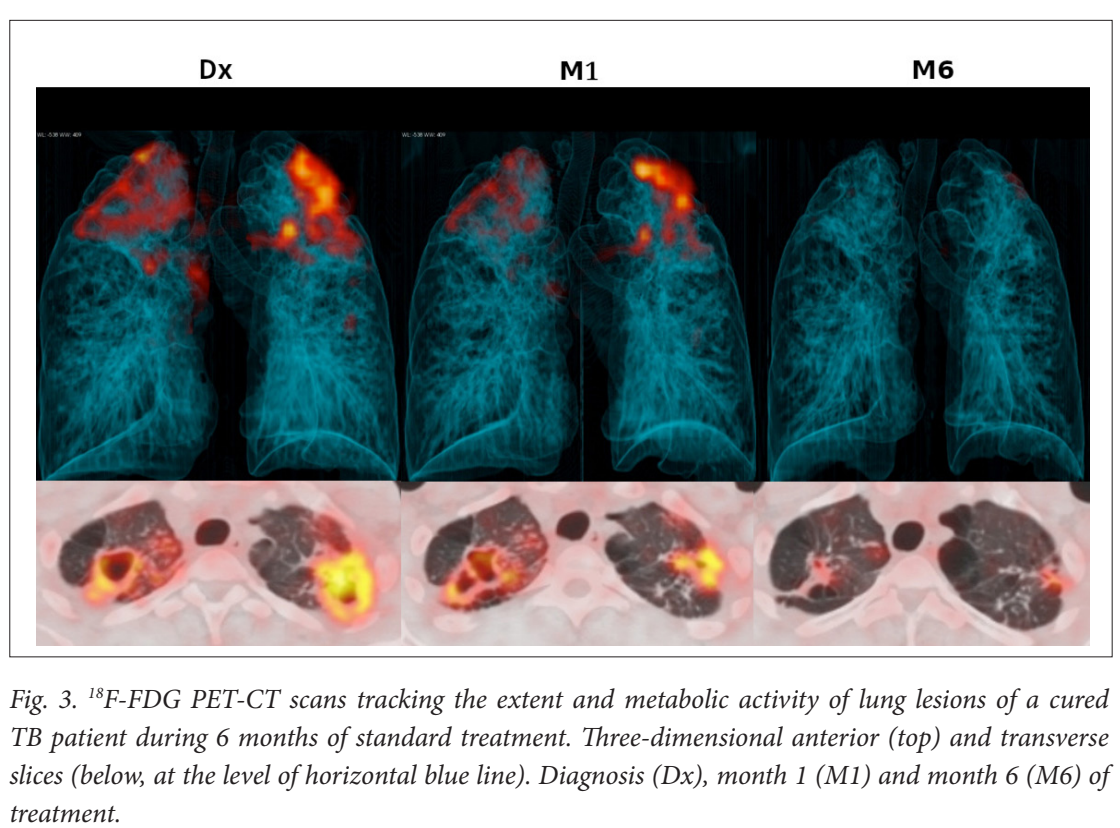

Fig. 3. ${ }^{18}$ F-FDG PET-CT scans tracking the extent and metabolic activity of lung lesions of a cured TB patient during 6 months of standard treatment. Three-dimensional anterior (top) and transverse slices (below, at the level of horizontal blue line). Diagnosis (Dx), month 1 (M1) and month 6 (M6) of treatment.

phase-dependent antigens had potential to be used as diagnostic tools for TB (International Patent: PCT/IB2013/054377; US $14 / 403,659)$. In the course of conducting validation studies on these biosignatures in other African countries, however, we noticed that biomarkers detectable in unstimulated blood samples may be more promising than antigen-stimulated biomarkers, besides being more promising as point-of-care diagnostic tests. We identified and validated host protein biosignatures from serum samples which showed strong potential for further development into a point-of-care test for TB (International Patent Application No.s: PCT/ IB2017/052142 and PCT/IB2015/051435) ${ }^{[48]}$ and have successfully developed a pointof-care fingerprick test based on these biomarkers in collaboration with our other African and European partners (www. screen-tb.eu). A clinical trial evaluating the utility of this fingerprick blood-based point-of-care test is currently ongoing in the participating African countries.

The use of positron emission tomography - computerised tomography (PET-CT) and translation of findings from PET-CT findings to more easily implementable tools for monitoring the response to $\mathrm{TB}$ treatment

In a ground-breaking study conducted at the CTR, PET-CT imaging technology was used to assess the progress of lesions in TB patients undergoing standard anti-TB therapy (Fig. 3). The technology was shown to be a useful tool to monitor the response of patients to treatment, through healing of the granulomatous lesions or appearance of 
new ones on the images, with PET-CT images that are consistent with active TB still present in the lungs of several presumed cured patients at the end of treatment. ${ }^{[49]}$ The interpretation of this finding is not yet clear, but may have serious implications and be useful as a monitoring tool for trials. These imaging patterns correlated with the presence of $M$. tuberculosis mRNA in sputum and broncho-alveolar lavage specimens from these patients at the end of treatment. A randomised controlled trial is currently ongoing in field sites in the Western Cape (SA) and China, aimed at employing PEC-CT imaging and the GeneXpert test results as a TB treatment-shortening tool (www. predict-tb.com). ${ }^{[50]}$ The ultimate aim of the project, which is currently ongoing, is the identification of easily measurable biomarkers that can be used as replacement tools for PET-CT at the point of care.

\section{Clinical trials}

TASK Applied Sciences (http://task.org.za), today an extramural clinical research unit with more than 150 employees, had its origins in the CTR. We knew that evaluation of new candidate antibiotics would be important and, to this end, initiated planning for a clinical trial team to be led by Professor Andreas Diacon. At this time, a team led by Koen Andries at Janssen in Beerse, Belgium, discovered a new potential antibiotic active against $M$. tuberculosis. ${ }^{[87]}$ Preclinical results with TMC207 (bedaquiline) looked promising, but the team hit a roadblock when looking for institutions that could assist with establishing proof-of-concept in actual TB patients. A decades-long dearth of clinical anti-TB drug evaluation had extinguished almost all such research capacity. Moreover, rigorous ethical and methodological standards now applied to testing of new pharmaceuticals. New methods were needed to create evidence of efficacy and safety for a new TB antibiotic. Only registration with strict regulatory authorities would eventually allow the people who needed those drugs to access them. Our team and MRC colleagues in Durban responded and showed that bedaquiline indeed reduced the number of mycobacteria in sputum within the first week of treatment. ${ }^{[29]}$ This work established clinical proof-of-concept for the first new anti-TB treatment in decades. Other projects with new or repurposed antibiotics followed in quick succession. The CTR supported the first formal clinical trials in drug-resistant TB that TASK conducted with bedaquiline in Brooklyn Chest Hospital, Cape Town. These studies were instrumental in obtaining registration for bedaquiline in 2012. ${ }^{[45,88]}$ The drug has since saved the lives of many patients infected with TB resistant to conventional agents and is now becoming a standard agent in new regimens. Such early bactericidal activity studies for proof-of-concept have become the standard method endorsed by both the US Federal Drug Administration and the European Medicines Agency. TASK, assisted by the University of Cape Town Lung Institute, is now the leading centre for proof-of-concept studies in TB. It is good news that numerous other new or repurposed antibiotics for TB are currently undergoing such testing and are on their way to joining bedaquiline as treatment options. ${ }^{[33,37,89,90]}$ It is very likely that in a few years we will have shorter, safer and better-tolerated treatment regimens available for treatment of TB of various resistance profiles.

\section{Using next-generation sequencing technologies in clinical settings}

It is now clear that genetic background influences susceptibility or resistance to $\mathrm{TB}$. We have not yet progressed to being able to use this information for standard TB cases; however, in special cases, genetic tools are already being used. For patients suffering from rare genetic diseases, which can include children who present with BCGosis after vaccination, ${ }^{[25]}$ or multiple episodes of $\mathrm{TB}$, an accurate diagnosis is crucial for treatment and management. The problem is that some rare diseases often present with combinations of symptoms that are unfamiliar to the physicians treating them, making diagnosis challenging. It is estimated that up to $50 \%$ of people suffering from a rare genetic disease never receive a diagnosis. ${ }^{[91]}$ Often, these patients have embarked on a 'diagnostic odyssey' that includes consultations with several specialists, a number of invasive interventions and expensive laboratory tests. This very slow process can incur crippling costs for the patient and may not yield the diagnosis they so desperately need, or not in time to benefit the patient.

With the significant reduction in the costs of next-generation DNA sequencing technology, we can now afford to use wholeexome sequencing (WES) in clinical settings to diagnose rare genetic disorders. At the CTR, a multidisciplinary team of researchers and physicians known as the Primary Immunodeficiency Disorders Genetics Research Group (PIDDGEN) has, since 2014, used WES to provide genetic diagnoses for patients with primary immunodeficiency disorders (PIDs). ${ }^{[56]}$ PIDs comprise over 300 different heritable disorders which are caused by inborn errors of the immune system that result in increased susceptibility to infection, autoimmunity, autoinflammation, allergy and tumours. PIDs are challenging to diagnose because of their variable clinical presentations but, in many cases, PIDDGEN has already been able to make a definitive diagnosis only through WES. ${ }^{[51,92,93]}$

One such case clearly illustrates the value of WES for diagnosis of PIDs: Patient CE, a young girl from a non-consanguineous marriage, was at two years of age diagnosed with humoral immunodeficiency after presenting with a BCG abscess on the upper leg. CE was placed on intravenous immunoglobulin replacement therapy, but developed BCG meningitis a year later. She subsequently received acute-phase INH, RIF, ETH and dexamethasone treatments and thereafter only INH and RIF. Two years later, the patient presented with acute loss of consciousness and raised intracranial pressure. BCG, genotypically sensitive to all the above prescribed drugs, was cultured from the patient. Immunological workup showed slightly elevated CD4 and B cell levels, with normal T cell proliferations to a range of different mitogens and recall antigens, as well as normal IFN- $\gamma$ production by T cells. Slightly low CD 8 and NK cell levels were observed, with decreased up-regulation of CD69 on NK cells after IL-2 stimulation. T cell receptor excision circles (TRECs) and kappa-deleting recombination excision circles (KRECs) were clearly visible. Class-switched memory B cells also remained persistently low. The patient's memory $\mathrm{T}$ cells were low in relation to the naïve $\mathrm{T}$ cells and, interestingly, reduced levels of $\gamma / \delta$ T cells were also observed cells involved in the innate immune reaction against mycobacteria. Exome sequencing of the patient identified a mutation in the NF- $\kappa \mathrm{B}$ inducing kinase (NIK) encoding gene, MAP3K14 (homozygous NIKVal345Met). Both parents of this patient were heterozygous carriers of the mutation. Using an overexpression cell model to mimic the effects of the mutations, we showed that the mutation significantly impaired the ability of NIK to phosphorylate IKKa. ${ }^{[51]}$

Subsequent to this finding, we identified the same mutation in another patient presenting with destructive pneumonia and hypogammaglobulinaemia. Both parents were heterozygous carriers of the mutation. This already BCG-vaccinated patient is being monitored closely for any evidence of developing dissemination. A further infant sibling was shown to be negative for the variant.

This case highlights the potential impact of next-generation sequencing (NGS) techniques such as WES on patient care. The integration of WES into clinical settings will enable accurate molecular diagnosis for patients suffering from diseases with unclear phenotypes or atypical presentation. NGS technologies are providing significant opportunities to implement personalised health strategies such as 


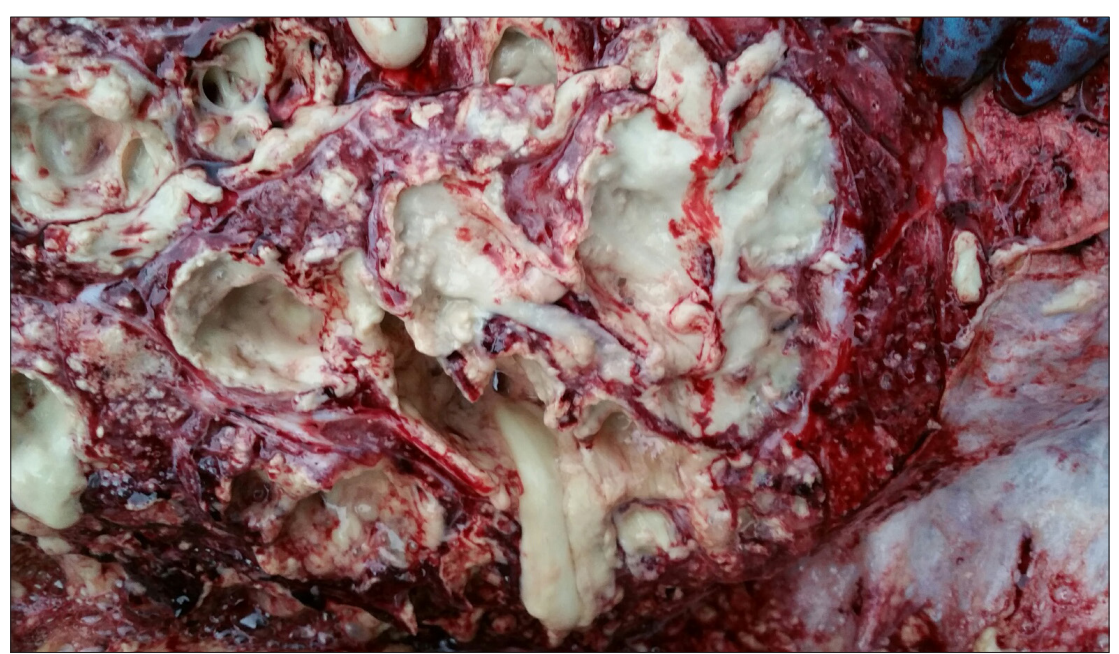

Fig. 4. Gross pathological changes in the lungs of an African elephant with M. tuberculosis disease. Lung lesions consist of multifocal to coalescing encapsulated cavities (10-15 cm in diameter).

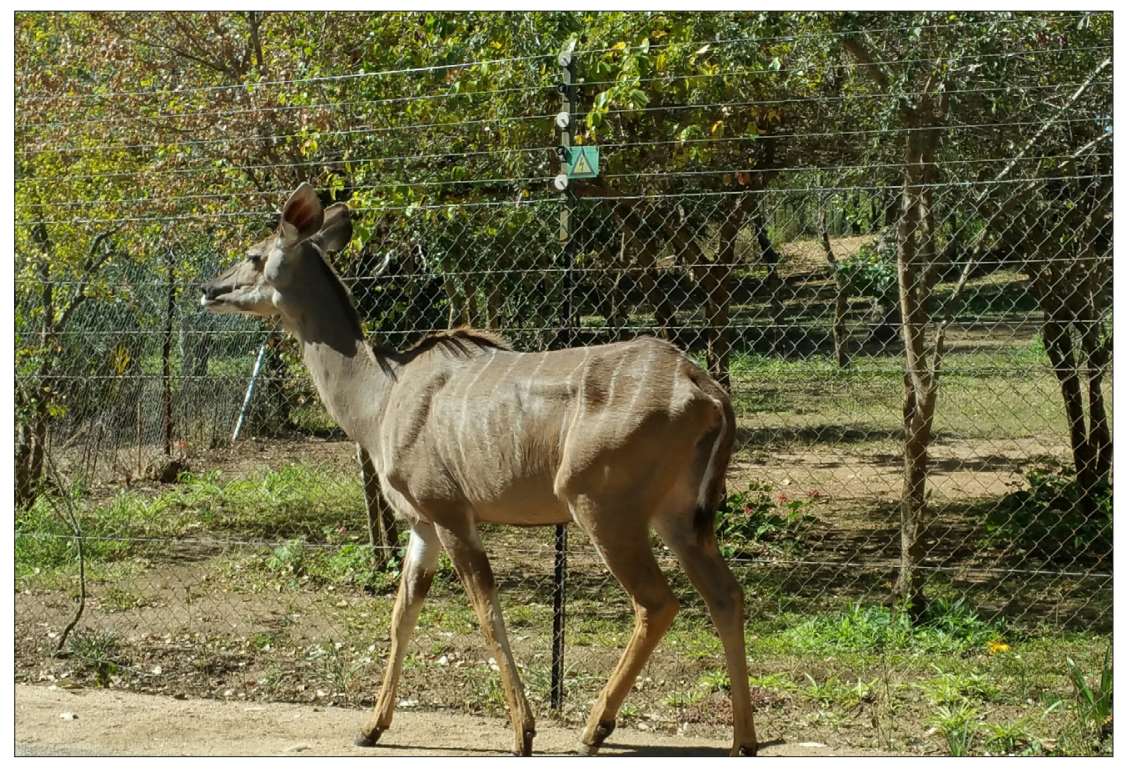

Fig. 5. Multiple subcutaneous lumps caused by bovine tuberculosis (bTB)-infected lymph nodes in the parotid area of a greater kudu cow. A frequent citing in areas endemic for bTB such as Kruger National Park (Limpopo) and Hluhluwe-iMfolozi Park (KwaZulu-Natal).

the early detection of disease, improved health maintenance and tailored therapies, particularly for patients with rare genetic diseases.

\section{Tuberculosis in animals}

Zoonotic TB was a major component of TB in years gone by, prompting public health efforts such as milk pasteurisation and slaughter of infected livestock to reduce prevalence. TB in livestock has become increasingly recognised as a global problem with serious economic and conservation implications. For this reason, the CTR began investigations into this topic some years ago. In SA, implementation of the CTR Animal TB Group's newly developed bovine tuberculosis (bTB) diagnostic assays such as the QuantiFERON TB-Gold Plus
IFN- $\gamma$ assays and IFN- $\gamma$ induced protein of $10 \mathrm{kDa}$ (IP-10) assays are now routinely used by conservation organisations such as Hluhluwe iMfolozi Park (HiP) and Kruger National Park (KNP) for the detection of bTB in African buffaloes (Fig. 4). ${ }^{[54,94-96]}$ For the past 11 years, the Animal TB Group has been successfully involved in HiP's annual African buffalo bTB reduction programme, which has resulted in a significantly reduced bTB prevalence in this species. In KNP, recent discoveries of bTB in African rhinoceros led to South African National Parks (SANParks) developing a TB management policy based on the Animal TB Group's research for these species and various others. ${ }^{[97-99]}$ Discovery of bovine $\mathrm{TB}$ in rhinoceros has prompted the Department of Agriculture, Forestry and Fisheries (DAFF) to place a moratorium on movement of these animals from known infected areas, with negative consequences for conservation. Speciation tests developed in the CTR are now used in the only routine service DAFF-accredited laboratory in SA. This work and other developments have led to far more accurate diagnosis in animals and has overturned assumptions in many interesting cases, for example our finding of $M$. tuberculosis in a free-ranging African elephant in KNP. ${ }^{[100]}$ The CTR has also described two entirely new species of pathogenic mycobacteria in this process. ${ }^{[101,102]}$

Research in a wide variety of animals including African wild dogs, African lions, antelope such as the greater kudu (Fig. 5), warthogs, hyenas and domestic livestock ${ }^{[103-106]}$ has drawn the attention of not only the Wildlife Ranching Association of SA, but also that of various private international zoos. We provide ongoing assistance to DAFF, SANParks, the National Zoological Gardens and others, such as the Namibian Wildlife Service, regarding TB in wild and domestic animals. In addition, this research provides a foundation for understanding the risk of zoonotic transmission of $M$. bovis, as emphasised in the WHO 'Roadmap for Zoonotic TB! ${ }^{[107]}$

\section{Conclusion}

Critical initial research findings of the CTR were that the SA TB epidemic was being driven by diverse, highly transmissible strains, harbouring resistance-associated mutations and accumulating further resistance owing to sub-optimal treatment. The epidemic was clearly not under control and therefore we believed that our understanding of disease dynamics was faulty. This view directed the early research agenda towards diagnostics, antibiotic use and resistance, ${ }^{[108]}$ in line with WHO TB research priorities (diagnostics, drugs and vaccines) ${ }^{[109]}$ as well as molecular epidemiology. Our work subsequently expanded to include epidemiology, bacteriology, genetics, immunology and the various 'omics' technologies that are now well known. We have used these tools in basic research, but also for direct and individual bench-to-bedside healthcare, and also to understand the dynamics of the disease in order to best design intervention and prevention strategies. In this context, CTR research findings have highlighted incorrect assumptions, led to improved understanding and, in the process, inspired ourselves and others to contribute towards $\mathrm{TB}$ research in new ways. We firmly believe that the CTR's research has shaped our knowledge and helped us to avoid continuing the mistakes of the past. 
Acknowledgements. We thank the members of the SAMRC Centre for Tuberculosis Research and their collaborators for their contribution to tuberculosis research over the past 30 years.

Author contributions. RMW, NI, NNC, GT, GW, STM, CJK, GDvdS, WG, MM, AHD and PDvH wrote the manuscript. RMW, NI and PDvH edited the final draft.

Conflict of interest. None.

Funding. This work was supported by the South African Medical Research Council, DST-NRF Centre of Excellence for Biomedical Tuberculosis Research, and NRF South African Research Chair Initiative (SARChI).

1. World Health Organization. TB: A global emergency, WHO report on the TB epdiemic. Geneva: WHO, 1994

2. Weyer K. Case study: South Africa. WHO Bull 2007;85(5):325-420

3. Van Rensburg D, van Rensburg-Bonthuyzen EJ, Heunis C, Meulemans H. Tuberculosis control in South Africa: Reasons for persistent failure. Acta Academica Supplementum 2005;1:1-55.

4. Van Helden PD, Warren RM, Uys P, van der Spuy GD, Victor TC. The molecular epidemiology of MDR-TB. In: Gillespie SH (ed.). Management of multiple drug-resistant infections. Totowa, NJ: Humana Press, 2004; 225-242.

Warren R, Richardson M, Sampson S, et al. Genotyping of Mycobacterium tuberculosis with additional markers enhances accuracy in epidemiological studies. J Clin Microbiol 1996;34(9):2219-2224.

6. Van Embden JD, Cave MD, Crawford JT, et al. Strain identification of Mycobacterium tuberculosis by DNA fingerprinting: recommendations for a standardized methodology. J Clin Microbiol 1993;31(2):406-409.

7. Warren R, Richardson M, van der Spuy G, et al. DNA fingerprinting and molecular epidemiology of tuberculosis: Use and interpretation in an epidemic setting. Electrophoresis 1999;20(8):1807-1812. https://doi.org/10.1002/(sici)1522-2683(19990101)20:8<1807::Aid-elps1807>3.0.Co;2-9

8. Warren RM, Streicher EM, Charalambous S, et al. Use of spoligotyping for accurate classification of recurrent tuberculosis. J Clin Microbiol 2002;40(10):3851-3853, https://doi.org/10.1128/ jcm.40.10.3851-3853.2002

9. Streicher EM, Victor TC, van der Spuy G, et al. Spoligotype signatures in the Mycobacterium tuberculosis complex. J Clin Microbiol 2007;45(1):237-240. https://doi.org/10.1128/jcm.01429-06

10. Kamerbeek J, Schouls L, Kolk A, et al. Simultaneous detection and strain differentiation of Mycobacterium tuberculosis for diagnosis and epidemiology. J Clin Micriobiol 1997;35(4):907-914.

11. Savine E, Warren RM, van der Spuy GD, et al. Stability of variable-number tandem repeats of mycobacterial interspersed repetitive units from 12 loci in serial isolates of Mycobacterium tuber
J Clin Micriobiol 2002;40(12):4561-4566. https://doi.org/10.1128/JCM.40.12.4561-4566.2002

12. Ramaswamy S, Musser JM. Molecular genetic basis of antimicrobial agent resistance in Mycobacterium . Ramaswamy S, Musser JM. Molecular genetic basis of antimicrobial agent resistance in Mycobacterium
tuberculosis: 1998 update. Tubercle Lung Dis 1998;79(1):3-29. https://doi.org/10.1054/tuld.1998.0002

tuberculosis: 1998 update. Tubercle Lung Dis 1998;79(1):3-29. https://doi.org/10.1054/tuld.1998.0002
13. Cole ST, Brosch R, Parkhill J, et al. Deciphering the biology of Mycobacterium tuberculosis from the Cole ST, Brosch R, Parkhill J, et al. Deciphering the biology of Mycobacterium tuberculosis
complete genome sequence. Nature 1998;393(6685):537-544. https://doi.org/10.1038/31159

complete genome sequence. Nature 1998;393(6685):537-544. https://doi.org/10.1038/31159
14. Van Rie A, Warren RM. MDR tuberculosis control: Time to change the dogma? Lancet Respir Med Van Rie A, Warren RM. MDR tuberculosis control: Time to change
2015;3(12):907-909. https://doi.org/10.1016/s2213-2600(15)00477-4

15. Van Rie A, Warren R, Richardson M, et al. Exogenous reinfection as a cause of recurrent tuberculosis an Rie A, Warren R, Richardson M, et al. Exogenous reinfection as a cause of recurrent tuberculosis
after curative treatment. N Engl J Med 1999;341(16):1174-1179. http://www.ncbi.nlm.nih.gov/ after curative trea
pubmed/10519895

16. Streicher EM, Warren RM, Kewley C, et al. Genotypic and phenotypic characterization of drugresistant Mycobacterium tuberculosis isolates from rural districts of the Western Cape Province of resistant Mycobacterium tuberculosis isolates from rural districts of the Western Cape Prov
South Africa. J Clin Microbiol 2004;42(2):891-894. https://doi.org/10.1128/jcm.42.4.1862.2004

South Africa. J Clin Microbiol 2004;42(2):891-894. https://doi.org/ $10.1128 / \mathrm{jcm} .42 .4 .1862 .2004$
17. Van Rie A, Warren R, Richardson M, et al. Exogenous reinfection as a cause of recurrent Van Rie A, Warren R, Richardson M, et al. Exogenous reinfection as a cause of recurrent
tuberculosis after curative treatment. N Engl J Med 1999;341(16):1174-1179. https://doi.org/10.1056/ tuberculosis after curative
nejm 199910143411602

18. Warren RM, Victor TC, Streicher EM, et al. Patients with active tuberculosis often have different strains in the same sputum specimen. Am J Respir Crit Care Med 2004;169(5):610-614. https://doi. $\mathrm{rg} / 10.1164 / \mathrm{rccm} .200305-7140 \mathrm{OC}$

19. Van Rie A, Victor TC, Richardson M, et al. Reinfection and mixed infection cause changing Mycobacterium tuberculosis drug-resistance patterns. Am J Respir Crit Care Med 2005;172(5):636-642. https://doi.org/10.1164/rccm.200503-4490

20. Van Helden PD, Toit R, Jordaan A, Taljaard B, Pitout J, Victor T. The use of the polymerase chain reaction test in the diagnosis of tuberculosis. S Afr Med J 1991;80(10):515-516.

21. Rossouw M, Nel HJ, Cooke GS, van Helden PD, Hoal EG. Association between tuberculosis and a polymorphic NFkappaB binding site in the interferon gamma gene. Lancet 2003;361(9372):1871-1872. https://doi.org/10.1016/s0140-6736(03)13491-5

22. Schaaf HS, Michaelis IA, Richardson M, et al. Adult-to-child transmission of tuberculosis: household or community contact? Int J Tuberc Lung Dis 2003;7(5):426-431.

23. Verver S, Warren RM, Munch Z, et al. Proportion of tuberculosis transmission that takes place in households in a high-incidence area. Lancet 2004;363(9404):212-214. https://doi.org/10.1016/s01406736(03) $15332-9$

24. Verver S, Warren RM, Beyers N, et al. Rate of reinfection tuberculosis after successful treatment is higher than rate of new tuberculosis. Am J Respir Crit Care Med 2005;171(12):1430-1435. https://doi. org/10.1164/rccm.200409-12000C

25. Hesseling AC, Rabie H, Marais BJ, et al. Bacille Calmette-Guerin vaccine-induced disease in HIV-infected and HIV-uninfected children. Clin Infect Dis 2006;42(4):548-558. https://doi. org/10.1086/499953

26. Barreiro LB, Neyrolles O, Babb CL, et al. Promoter variation in the DC-SIGN-encoding gene CD209 is associated with tuberculosis. PLoS Med 2006;3(2):e20. https://doi.org/10.1371/journal.pmed.0030020

27. Babb C, van der Merwe L, Beyers N, et al. Vitamin D receptor gene polymorphisms and sputum conversion time in pulmonary tuberculosis patients. Tuberculosis 2007;87(4):295-302. https://doi. org/10.1016/.jtube.2007.03.001

28. Chegou NN, Walzl G, Bolliger CT, Diacon AH, van den Heuvel MM. Evaluation of adapted wholeblood interferon-gamma release assays for the diagnosis of pleural tuberculosis. Respiration 2008; 76(2):131-138. https://doi.org/10.1159/000128575

29. Rustomjee R, Diacon AH, Allen J, et al. Early bactericidal activity and pharmacokinetics of the diarylquinoline TMC207 in treatment of pulmonary tuberculosis. Antimicrob Agents Chemother 2008;52(8):2831-2835. https://doi.org/10.1128/AAC.01204-07

30. Chegou NN, Black GF, Kidd M, van Helden PD, Walzl G. Host markers in QuantiFERON supernatants differentiate active TB from latent TB infection: Preliminary report. BMC Pulm Med 2009;9:21. https://doi.org/10.1186/1471-2466-9-21

31. Warren RM, Streicher EM, Gey van Pittius NC, et al. The clinical relevance of Mycobacterial pharmacogenetics. Tuberculosis 2009;89(3):199-202. https://doi.org/10.1016/j.tube.2009.03.001

pharmacogenetics. Tuberculosis 2009;89(3):199-202. https:// doi.org/10.1016/j.tube.2009.03.001
32. Walzl G, Chegou NN, Ndong PE. Method for diagnosing tuberculosis disease by detecting induced markers after stimulation of T-cells with antigens. WO/2013/175459 A2. 27 May 2013.
33. Diacon AH, Dawson R, Hanekom M, et al. Early bactericidal activity and pharmacokinetics of PA-824 in smear-positive tuberculosis patients. Antimicrob Agents Chemother 2010;54(8):3402-3407. https:// doi.org/10.1128/AAC.01354-09

34. Ligthelm LJ, Nicol MP, Hoek KGP, et al. Xpert MTB/RIF for rapid diagnosis of tuberculous lymphadenitis from fine-needle-aspiration biopsy specimens. J Clin Microbiol 2011;49(11):3967-3970 https://doi.org/10.1128/JCM.01310-11

35. Gallant CJ, Cobat A, Simkin L, et al. Impact of age and sex on mycobacterial immunity in an area of high tuberculosis incidence. Int J Tuberc Lung Dis 2010;14(8):952-959.

36. Parsons SD, Cooper D, McCall AJ, et al. Modification of the QuantiFERON-TB Gold (In-Tube) assay for the diagnosis of Mycobacterium bovis infection in African buffaloes (Syncerus caffer). Vet Immuno Immunopath 2011;142(1-2):113-118. https://doi.org/10.1016/j.vetimm.2011.04.006

37. Diacon AH, Dawson R, Von Groote-Bidlingmaier F, et al. 14-day bactericidal activity of PA824, bedaquiline, pyrazinamide, and moxifloxacin combinations: A randomised trial. Lancet 2012;380(9846):986-993. https://doi.org/10.1016/S0140-6736(12)61080-0

38. Barnard M, Warren R, Gey van Pittius N, et al. Genotype MTBDRsl line probe assay shortens time to diagnosis of extensively drug-resistant tuberculosis in a high-throughput diagnostic laboratory. Am Respir Crit Care Med 2012;186(12):1298-1305. https://doi.org/10.1164/rccm.201205-09600C

39. Streicher EM, Bergval I, Dheda K, et al. Mycobacterium tuberculosis population structure determines the outcome of genetics-based second-line drug resistance testing. Antimicrobial Agents Chemother 2012;56(5):2420-2427. https://doi.org/10.1128/AAC.05905-11

40. Chegou NN, Black GF, Loxton AG, et al. Potential of novel Mycobacterium tuberculosis infection phasedependent antigens in the diagnosis of TB disease in a high burden setting. BMC Infect Dis 2012;12:10. https://doi.org/10.1186/1471-2334-12-10

41. Muller B, Chihota VN, Pillay M, et al. Programmatically selected multidrug-resistant strains drive the Muller B, Chihota VN, Pillay M, et al. Programmatically selected multidrug-resistant strains drive the
emergence of extensively drug-resistant tuberculosis in South Africa. PloS One 2013;8(8):e70919. https:// emergence of extensively drug-resistant
doi.org/10.1371/journal.pone.0070919

42. Parsons SDC, Drewe JA, Gey van Pittius NC, Warren RM, van Helden PD. Novel cause of tuberculosis in meerkats, South Africa. Emerg Infect Dis 2013;19(12):2004-2007. https://doi.org/10.3201/eid1912.130268 Miller M, Olea-Popelka F. One Health in the shrinking world: Experiences with tuberculosis at the human-livestock-wildlife interface. Comp Immunol Microbiol Infect Dis 2013;36(3):263-268. https://doi org/10.1016/j.cimid.2012.07.005

4. Cobat A, Hoal EG, Gallant CJ, et al. Identification of a major locus, TNF1, that controls BCG-triggere tumor necrosis factor production by leukocytes in an area hyperendemic for tuberculosis. Clin Infect Dis 2013;57(7):963-970. https://doi.org/10.1093/cid/cit438

5. Diacon AH, Pym A, Grobusch MP, et al. Multidrug-resistant tuberculosis and culture conversion with bedaquiline. N Engl J Med 2014;371(8):723-732. https://doi.org/10.1056/NEJMoa1313865

46. Theron G, Peter J, Richardson M, et al. The diagnostic accuracy of the GenoType((R)) MTBDRsl assay for the detection of resistance to second-line anti-tuberculosis drugs. Cochrane Rev 2014(10):Cd010705. https://doi.org/10.1002/14651858.CD010705.pub2

47. Salie M, van der Merwe L, Moller M, et al. Associations between human leukocyte antigen class I variants and the Mycobacterium tuberculosis subtypes causing disease. J Infect Dis 2014;209(2):216-223. https:// doi.org/10.1093/infdis/jit443

48. Jacobs R, Malherbe S, Loxton AG, et al. Identification of novel host biomarkers in plasma as candidates for the immunodiagnosis of tuberculosis disease and monitoring of tuberculosis treatment response. for the immunodiagnosis of tuberculosis disease and monitoring of tuberculasis

49. Malherbe ST, Shenai S, Ronacher K, et al. Persisting positron emission tomography lesion activity and Mycobacterium tuberculosis mRNA after tuberculosis cure. Nature Med 2016;22(10):1094-1100. https:// doi.org/10.1038/nm.4177

50. Chen RY, Via LE, Dodd LE, et al. Using biomarkers to predict TB treatment duration (Predict TB): A prospective, randomized, noninferiority, treatment shortening clinical trial. Gates Open Res 2017;1:9. https://doi.org/10.12688/gatesopenres.12750.1

51. Schlechter N, Glanzmann B, Hoal EG, et al. Exome sequencing identifies a novel MAP3K14 mutation in recessive atypical combined immunodeficiency. Front Immunol 2017;8:1624. https://doi.org/10.3389 fimmu.2017.01624

52. Parsons SDC, Morar-Leather D, Buss P, et al. The kinetics of the humoral and interferon-gamma immun responses to experimental Mycobacterium bovis infection in the white rhinoceros (Ceratotherium simum). Front Immunol 2017;8:1831. https://doi.org/10.3389/fimmu.2017.01831

53. Metcalfe JZ, Streicher E, Theron G, et al. Cryptic microheteroresistance explains Mycobacterium tuberculosis phenotypic resistance. Am J Respir Crit Care Med 2017;196(9):1191-1201. https://doi. org/10.1164/rccm.201703-0556OC

54. Bernitz N, Clarke C, Roos EO, et al. Detection of Mycobacterium bovis infection in African buffaloes (Syncerus caffer) using QuantiFERON((R))-TB Gold (QFT) tubes and the Qiagen cattletype((R)) IFN-gamma ELISA. Vet Immunol Immunopathol 2018;196:48-52. https://doi.org/10.1016/j. IFN-gamma ELISA
vetimm. 2017.12 .010

55. Moller M, Flachsbart F, Till A, et al. A functional haplotype in the $3^{\prime}$ untranslated region of TNFRSF1B is associated with tuberculosis in two African populations. Am J Respir Crit Care Med 2010;181(4):388-393. https://doi.org/10.1164/rccm.200905-06780C

56. Glanzmann B, Uren C, de Villiers N, et al. Primary immunodeficiency diseases in a tuberculosis endemic region: challenges and opportunities. Genes Immun 2019;20(6):447-454. https://doi.org/10.1038/s41435018-0041-0

57. Schurz H, Kinnear CJ, Gignoux C, et al. A sex-stratified genome-wide association study of tuberculosis using a multi-ethnic genotyping array. Front Genet 2019;9:678. https://doi.org/10.3389/fgene.2018.00678 58. De Vos M, Ley SD, Wiggins K, et al. Bedaquiline micro-heteroresistance after tuberculosis treatmen cessation. N Engl J Med 2019;380(22):2178-2180. https://doi.org/10.1056\%2FNEJMc1815121

59. Victor TC, Jordaan AM, van Rie A, et al. Detection of mutations in drug resistance genes of Mycobacterium tuberculosis by a dot-blot hybridization strategy. Tubercle Lung Dis 1999;79(6):343-348. https://do org/10.1054/tuld.1999.0222

60. National Department of Health $(\mathrm{NDoH})$. Pocket book: Multi-drug resistant Tuberculosis. National Clinical Management Training. Pretoria: NDoH, 2018.

61. Theron G, Peter J, Richardson M, Warren R, Dheda K, Steingart KR. GenoType MTBDRsl assay for resistance to second-line anti-tuberculosis drugs. Cochrane Database Syst Rev 2016(9):CD010705. https:// doi.org/10.1002/14651858.CD010705.pub3

62. Barnard M, Albert H, Coetzee G, O’Brien R, Bosman ME. Rapid molecular screening for multidrugresistant tuberculosis in a high-volume public health laboratory in South Africa. Am J Respir Crit Care Med 2008;177(7):787-792. https://doi.org/10.1164/rccm.200709-1436OC

63. De Vos M, Derendinger B, Dolby T, et al. Diagnostic accuracy and utility of fluorotype MTBDR, a new molecular assay for multidrug-resistant tuberculosis. J Clin Microbiol 2018;56(9):e00531-e00518. https:/ doi.org/10.1128/icm.00531-18

64. Wright $\mathrm{C}$, Bamford $\mathrm{C}$, Prince $\mathrm{Y}$, et al. Mycobacterial transport medium for routine culture of fine needle aspiration biopsies. Arch Dis Child 2009;95(1):48-50. https://doi.org/10.1136/adc.2009.164038

65. Coetzee L, Nicol MP, Jacobson R, et al. Rapid diagnosis of pediatric mycobacterial lymphadenitis using fine needle aspiration biopsy. Pediatr Infect Dis J 2014;33(9):893-896. https://doi.org/10.1097 inf.0000000000000312

66. Sirgel FA, Tait M, Warren RM, et al. Mutations in the rrs A1401G gene and phenotypic resistance to amikacin and capreomycin in Mycobacterium tuberculosis. Microb Drug Resist 2012;18(2):193-197. https://doi.org/10.1089/mdr.2011.0063

67. Sirgel FA, Warren RM, Streicher EM, Victor TC, van Helden PD, Bottger EC. gyrA mutations and phenotypic susceptibility levels to ofloxacin and moxifloxacin in clinical isolates of Mycobacterium tuberculosis. J Antimicrob Chemother 2012;67(5):1088-1093. https://doi.org/10.1093/jac/dks033 
68. Johnson R, Jordaan AM, Pretorius L, et al. Ethambutol resistance testing by mutation detection. Int I Tuberc Lung Dis 2006;10(1):68-73

69. Sirgel FA, Warren RM, Streicher EM, Victor TC, van Helden PD, Bottger EC. gyrA mutations and phenotypic susceptibility levels to ofloxacin and moxifloxacin in clinical isolates of Mycobacterium tuberculosis. J Antimicrob Chemother 2012;67(5):1088-1093. https://doi.org/10.1093/jac/dks033

70. World Health Organization. Technical report on critical concentrations for TB drug susceptibility testing of medicines used in the treatment of drug-resistant TB. Geneva: WHO, 2018.

71. Warren RM, Streicher EM, Gey van Pittius NC, et al. The clinical relevance of mycobacterial pharmacogenetics. Tuberculosis 2009;89(3):199-202. https://doi.org/10.1016/j.tube.2009.03.001

72. Whitfield MG, Warren RM, Mathys V, et al. The potential use of rifabutin for treatment of patients diagnosed with rifampicin-resistant tuberculosis. J Antimicrob Chemother 2018;73(10):2667-2674 https://doi.org/10.1093/jac/dky248

73. Sirgel FA, Warren RM, Böttger EC, Klopper M, Victor TC, van Helden PD. The rationale for using rifabutin in the treatment of MDR and XDR tuberculosis outbreaks. PloS One 2013;8(3):e59414. https://doi.org/10.1371/journal.pone.0059414

74. Streicher EM, Maharaj K, York T, et al. Rapid sequencing of the Mycobacterium tuberculosis pncA gene for detection of pyrazinamide susceptibility. J Clin Microbiol 2014;52(11):4056-4057. https://doi. gene for detection of pyra
org $/ 10.1128 / \mathrm{jcm} .02438-14$

75. Whitfield MG, Streicher EM, Dolby T, et al. Prevalence of pyrazinamide resistance across the spectrum of drug resistant phenotypes of Mycobacterium tuberculosis. Tuberculosis 2016;99:128-130. https://doi. of drug resistant phenotypes of $M$.
org $/ 10.1016 /$ j.tube. 2016.05 .003

76. Ezewudo M, Borens A, Chiner-Oms Á, et al. Integrating standardized whole genome sequence analysis with a global Mycobacterium tuberculosis antibiotic resistance knowledge base. Scientific Rep 2018;8(1):15382. https://doi.org/10.1038/s41598-018-33731-1

77. Miotto P, Tessema B, Tagliani E, et al. A standardised method for interpreting the association between mutations and phenotypic drug resistance in Mycobacterium tuberculosis. Eur Respir 2017;50(6):1701354. https://doi.org/10.1183/13993003.01354-2017

78. Reeve BWP, McFall SM, Song R, Warren R, Steingart KR, Theron G. Commercial products to preserve specimens for tuberculosis diagnosis: A systematic review. Int J Tuberc Lung Dis 2018;22(7):741-753. https://doi.org/10.5588/ijtld.17.0816

79. Naidoo P, Theron G, Rangaka MX, et al. The South African tuberculosis care cascade: Estimated losses and methodological challenges. J Infect Dis 2017:216(Suppl 7):S702-S713, https://doi.org/10.1093/ infdis/jix 335

80. Venter R, Derendinger B, de Vos M, et al. Mycobacterial genomic DNA from used Xpert MTB RIF cartridges can be utilised for accurate second-line genotypic drug susceptibility testing and RIF cartridges can be utilised for accurate second-line genotypic drug susceptibility
spoligotyping. Scientific Rep 2017;7(1):14854. https://doi.org/10.1038/s41598-017-14385-x

81. Derendinger B, de Vos M, Nathavitharana RR, et al. Widespread use of incorrect PCR ramp 1. Derendinger B, de Vos M, Nathavitharana RR, et al. Widespread use of incorrect PCR ramp
rate negatively impacts multidrug-resistant tuberculosis diagnosis (MTBDRplus). Scientific Rep rate negatively impacts multidrug-resistant tuberculosis
2018;8(1):3206. https://doi.org/10.1038/s41598-018-21458-

2018;8(1):3206. https://doi.org/10.1038/s41598-018-21458-y
Joshi R, Pai M. Can pleural tuberculosis be diagnosed using interferon-gamma release assays? 2. Joshi R, Pai M. Can pleural tuberculosis be diagnosed using
Respiration 2008;76(2):128-130. https://doi.org/10.1159/00013593

3. McNerney R, Cunningham J, Hepple P, Zumla A. New tuberculosis diagnostics and rollout. Int I Infect Dis 2015;32:81-86. https://doi.org/10.1016/j.jid.2015.01.012

84. Hesseling AC, Mandalakas AM, Kirchner HL, et al. Highly discordant T cell responses in individuals with recent exposure to household tuberculosis. Thorax 2009;64(10):840-846. https://doi.org/10.1136/ thx.2007.085340

85. Mazurek GH, Jereb J, Vernon A, et al. Updated guidelines for using Interferon Gamma Release Assays to detect Mycobacterium tuberculosis infection - United States, 2010. MMWR Recomm Rep 2010;59(RR-5):1-25

86. Pozniak AL, Coyne KM, Miller RF, et al. British HIV Association guidelines for the treatmen of TB/HIV coinfection 2011. HIV Med 2011;12(9):517-524. https://doi.org/10.1111/j.14681293.2011.00954.x

87. Andries K, Verhasselt P, Guillemont J, et al. A diarylquinoline drug active on the ATP synthase of Mycobacterium tuberculosis. Science 2005;307(5707):223-227. https://doi.org/10.1126/science.110675

8. Diacon AH, Pym A, Grobusch M, et al. The diarylquinoline TMC207 for multidrug-resistan tuberculosis. N Engl J Med 2009;360(23):2397-2405. https://doi.org/https://doi.org/10.1056/ nejmoa 0808427
89. Heinrich N, Dawson R, du Bois J, et al. Early phase evaluation of SQ109 alone and in combination with rifampicin in pulmonary TB patients. J Antimicrob Chemother 2015;70(5):1558-1566. https:// doi.org/10.1093/jac/dku553

90. Diacon AH, Dawson R, Hanekom M, et al. Early bactericidal activity of delamanid (OPC-67683) in smear-positive pulmonary tuberculosis patients. Int J Tuberc Lung Dis 2011;15(7):949-954. https:// doi.org/10.5588/ijtld.10.0616

91. Boycott KM, Vanstone MR, Bulman DE, MacKenzie AE. Rare-disease genetics in the era of nextgeneration sequencing: discovery to translation. Nat Rev Genetics 2013;14(10):681-691. https://doi. org/10.1038/nrg3555

92. Kinnear C, Glanzmann B, Banda E, et al. Exome sequencing identifies a novel TTC37 mutation in the first reported case of Trichohepatoenteric syndrome (THE-S) in South Africa. BMC Med Genet 2017;18(1):26. https://doi.org/10.1186/s12881-017-0388-5

93. Glanzmann B, Moller M, Moncada-Velez M, et al. Autosomal dominant ifn-gammarl deficiency presenting with both atypical mycobacteriosis and tuberculosis in a BCG-vaccinated South African patient. J Clin Immunol 2018:38(4):460-463. https://doi.org/10.1007/s10875-018-0509-8

94. Bernitz N, Goosen WJ, Clarke C, et al. Parallel testing increases detection of Mycobacterium bovisinfected African buffaloes (Syncerus caffer). Vet Immunol Immunolpath 2018;204:40-43. https://doi, org/10.1016/j vetimm.2018.09.004

95. Goosen WJ. Miller MA, Chegou NN, et al. Agreement between assays of cell-mediated immunity utilizing Mycobacterium bovis-specific antigens for the diagnosis of tuberculosis in African buffaloes (Syncerus caffer). Vet Immunol Immunolpath 2014;160(1-2):133-138. https://doi.org/10.1016/j. etimm.2014.03.015

96. Goosen WJ, Cooper D, Miller MA, van Helden PD, Parsons SD. IP-10 is a sensitive biomarker of antigen recognition in whole-blood stimulation assays used for the diagnosis of Mycobacterium bovis infection in African buffaloes (Syncerus caffer). Clin Vaccine Immunol 2015;22(8):974-978. https:// doi.org/10.1128/CVI.00324-15

97. Miller M, Buss P, Hofmeyr J, Olea-Popelka F, Parsons S, van Helden P. Antemortem diagnosis of Mycobacterium bovis infection in free-ranging African lions (Panthera leo) and implications for transmission. J Wildl Dis 2015;51(2):493-497. https://doi.org/10.7589/2014-07-170

98. Miller MA, Greenwald R, Lyashchenko KP. Potential for serodiagnosis of tuberculosis in black thinoceros (Diceros bicornis). J Zoo Wildl Med 2015:46(1):100-104. https://doi.org/10.1638/2014$0172 \mathrm{R} 1.1$

99. Miller M, Michel A, van Helden P, Buss P. Tuberculosis in rhinoceros: An underrecognized threat? Transbound Emerg Dis 2017;64(4):1071-1078. https://doi.org/10.1111/tbed.12489

100. Miller MA, Buss P, Roos EO, et al. Fatal tuberculosis in a free-ranging African elephant and one health implications of human pathogens in wildlife. Front Vet Sci 2019;6:18. https://doi.org/10.3389/ fvets. 2019.00018

101. Alexander KA, Laver PN, Michel AL, et al. Novel Mycobacterium tuberculosis complex pathogen, $M$. mungi. Emerg Infect Dis 2010;16(8):1296-1299. https://doi.org/10.3201/eid1608.100314

102. Dippenaar A, Parsons SDC, Sampson SL, et al. Whole genome sequence analysis of Mycobacterium suricattae. Tuberculosis 2015;95(6):682-688. https://doi.org/10.1016/j.tube.2015.10.001

103. Higgitt RL, van Schalkwyk OL, de Klerk-Lorist LM, et al. An interferon gamma release assay for the detection of immune sensitization to Mycobacterium bovis in African wild dogs (Lycaon Pictus). J Wildl Dis 2019;55(3):529-536. https://doi.org/10.7589/2018-03-089

104. Olivier TT, Viljoen IM, Hofmeyr J, et al. Development of a gene expression assay for the diagnosis of Mycobacterium bovis infection in African lions (Panthera leo). Transbound Emerg Dis 2017;64(3):774781. https://doi.org/10.1111/tbed.12436

105. Parsons SD, McGill K, Doyle MB, Goosen WJ, van Helden PD, Gormley E. Antigen-specific IP-10 release is a sensitive biomarker of Mycobacterium bovis infection in cattle. PloS One 2016;11(5):e0155440. https://doi.org/10.1371/journal.pone.0155440

106. Roos EO, Buss P, de Klerk-Lorist LM, et al. Test performance of three serological assays for the detection of Mycobacterium bovis infection in common warthogs (Phacochoerus africanus). Vet Immunol Immunopath 2016;182:79-84. https://doi.org/10.1016/j.vetimm.2016.10.006

107. World Health Organization. WHO roadmap for zoonotic tuberculosis. Geneva: WHO, 2017.

108. Van Helden PD, Donald PR, Victor TC, et al. Antimicrobial resistance in tuberculosis: An international perspective. Expert Rev Anti Infect Ther 2006;4(5):759-766. https://doi.org/10.1586/14787210.4.5.759 109. World Health Organization. Priorities for tuberculosis research. Geneva: WHO, 2013. 